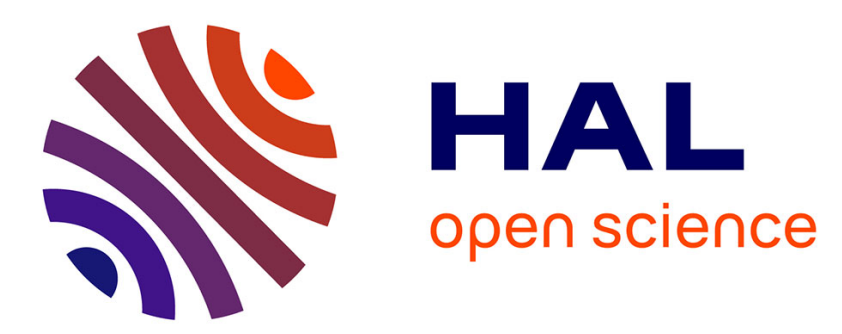

\title{
A new class of Dy(III)-SIMs associated with a guanidine-based ligand
}

Basharat Ali, Xiao-Lei Li, Frédéric Gendron, Boris Le Guennic, Jinkui Tang

\section{To cite this version:}

Basharat Ali, Xiao-Lei Li, Frédéric Gendron, Boris Le Guennic, Jinkui Tang. A new class of Dy(III)SIMs associated with a guanidine-based ligand. Dalton Transactions, 2021, 50 (15), pp.5146-5153. 10.1039/d1dt00260k . hal-03193285

\section{HAL Id: hal-03193285 \\ https://hal.science/hal-03193285}

Submitted on 12 May 2021

HAL is a multi-disciplinary open access archive for the deposit and dissemination of scientific research documents, whether they are published or not. The documents may come from teaching and research institutions in France or abroad, or from public or private research centers.
L'archive ouverte pluridisciplinaire HAL, est destinée au dépôt et à la diffusion de documents scientifiques de niveau recherche, publiés ou non, émanant des établissements d'enseignement et de recherche français ou étrangers, des laboratoires publics ou privés. 


\section{A new class of Dy'III-SIMs associated with guanidine-based ligand}

Received 00th January 20xx Accepted 00th January 20xx DOI: $10.1039 / \mathrm{x} 0 \mathrm{xx} 00000 \mathrm{x}$

www.rsc.org/

\begin{abstract}
Basharat Ali, ${ }^{\text {a,b }}$ Xiao-Lei Li, ${ }^{a}$ Frédéric Gendron, ${ }^{\mathrm{c}}$ Boris Le Guennic ${ }^{* c}$ and Jinkui Tang*a,b
A family of four mononuclear Dy ${ }^{\text {III }}$ complexes of guanidine-based ligand $\mathrm{L}$ [ $\mathrm{L}=$ tris(2-hydroxybenzylidene)triaminoguanidine] with formulas [DyLCl $\left.2(\mathrm{DMF})_{2}\right] \cdot \mathrm{DMF} \cdot \mathrm{CH}_{3} \mathrm{OH}(1)$, [DyL $\left.\left.\left(\mathrm{CH}_{3} \mathrm{OH}\right)_{2}\right] \mathrm{Br} \cdot \mathrm{H}_{2} \mathrm{O} \cdot 3 \mathrm{CH}_{3} \mathrm{OH}(2),\left[\mathrm{DyL} 2\left(\mathrm{H}_{2} \mathrm{O}\right)_{2}\right] \mathrm{SCN} \cdot 3 \mathrm{H}_{2} \mathrm{O} \cdot \mathrm{CH}_{3} \mathrm{OH}\right)(3)$ and $\left[\right.$ DyL $\left.L_{2}\left(\mathrm{CH}_{3} \mathrm{OH}\right)_{2}\right] \mathrm{SCN} \cdot \mathrm{CH}_{3} \mathrm{CN} \cdot \mathrm{CH}_{3} \mathrm{OH}(4)$ were successfully prepared by fluctuating the reaction conditions. Complex 1 is seven coordinated, three $\left(\mathrm{N}_{2} \mathrm{O}\right)$ from ligand $\mathrm{L}$ along with two equatorially trapped $\mathrm{DMF}$ molecules and two axially $\mathrm{Cl}^{-}$anions, adopting pentagonal bipyramidal $D_{5 \mathrm{~h}}$ symmetry. While complexes 2-4 display somewhat similar structures with six donor $\mathrm{N}_{4} \mathrm{O}_{2}$ sites from two ligands and two $\mathrm{O}$ from the corresponding solvent molecules that feature a $\mathrm{N}_{4} \mathrm{O}_{4}$ octa-coordinate environment with triangular dodecahedron $D_{2 d}$ symmetry. Magnetic investigations evidenced that Complex 1 did not show single molecule magnetic behavior while complexes 2-4 are single-ion magnets (SIMs) under zero applied DC field with effective energy barriers $\left(U_{\text {eff }}\right)$ of 207.3 (2), 222.5 (3) and $311.7 \mathrm{~K}$ (4), respectively. The different types of coordinated solvent molecules and counter anions bring changes in the intermolecular interactions and the coordination geometries, which severely affect their magnetic dynamics. The magnetic behaviors of these complexes were investigated by means of complete-active space self-consistent field (CASSCF) calculations with inclusion of spin-orbit effects. Calculations reveal that the measured differences in magnetic behaviors originate mainly from intermolecular and crystal-packing effects as the isolated complexes 1-4 have almost identical electronic and magnetic properties.
\end{abstract}

\section{Introduction}

Single-molecule magnets (SMMs) are fascinating and tunable molecular systems, which show the ability to retain magnetization through an effective energy barrier $\left(U_{\text {eff }}\right)$, and hence display magnetic hysteresis of purely molecular origin. ${ }^{1-6}$ The strong spin-orbit coupling in some of the lanthanide ions (e.g. Tb"II, Dy'II, Ho'II and Er'II) causes large magnetic anisotropy, and is intensively used in the construction of high performance SMMs. ${ }^{7,8}$ Importantly, the assembling of appropriate SMMs strongly associates with the control of the coordination geometry around the single metal ion. ${ }^{9}$ Recently, the use of Dy"ll ions to generate a large magnetic anisotropy through the fundamental combination of theory and experiment has led to a novel class of SMMs with remarkable energy barriers and high blocking temperatures up to $80 \mathrm{~K} \cdot{ }^{10-12}$

These interesting features of SMMs at the molecular level make them potential candidates for molecular spintronics devices and high density information storage materials for the next-generation. ${ }^{13}$, 14 However, to make SMMs practically

\footnotetext{
a. State Key Laboratory of Rare Earth Resource Utilization, Changchun Institute of Applied Chemistry, Chinese Academy of Sciences, Changchun 130022, P. R. China b. School of Applied Chemistry and Engineering, University of Science and Technology of China, Hefei 230026, P. R. China

c. Univ Rennes, CNRS, ISCR (Institut des Sciences Chimiques de Rennes) - UMR 6226, F-35000 Rennes, France

†Electronic supplementary information (ESI) available: crystallographic data and magnetic characterization. CCDC 1999242 (1), 1999244 (2), 1999245 (3), 1999246 (4). For ESI and crystallographic data in CIF or other electronic format see DOI: 10.1039/x0xx00000x
}

applicable, one still needs to enhance the working temperature to retain their magnetization above the boiling point of liquid nitrogen. ${ }^{15}$ Previously, it was believed that the most appropriate strategy was to improve the spin value of the ground state. ${ }^{16}$ However, soon it was realized that the single-ion magnetic anisotropy is frequently canceled out within such molecule with high spin state, thus, resulting in only a small $U_{\text {eff }}{ }^{9}$ Alternatively, mononuclear SMMs, containing only one spin center, also called single-ion magnets (SIMs), allows scientists to investigate and control the single-ion magnetic anisotropy. Until now, researchers have successfully developed several SIMs by controlling the coordination environment and designing crystal fields and many productive results have been obtained. ${ }^{10-12,17-19}$

The slight changes in the coordination environment can significantly influence the magnetic properties of SMMs. For instance, alteration in lattice counter anions ${ }^{15}$ and solvent molecules ${ }^{20,} 21$ (the coordinated solvents and the lattice solvents) generates distinct magnetic relaxation processes. Consequently, lattice counter anions and/or coordinated solvent molecules may modulate the coordination environment, and play a significant role in molecular switches and designing high-performance magnets.

Guanidine-based $C_{3}$-symmetric ligands are important building blocks for the construction of supramolecular coordination cages. The coordination chemistry of transition metals based on such types of ligands has already been well established.22-27 Furthermore, the magnetochemistry of triangular building blocks carrying a rigid triaminoguanidine backbone with $3 \mathrm{~d}$ transition cations has also been explored 
very recently. ${ }^{28-34}$ Surprisingly, such types of ligands have never been used with $4 \mathrm{f}$ rare earth metals, except in a single study in which Eu'II and Gd"II based tetramers were obtained. ${ }^{35}$ Unexpectedly, by self-oxidation the inner core configuration of the ligand was totally changed as intra-ligand triazole cyclization was accrued during complexation. For the first time we have succeeded to synthesize a new family of four mononuclear Dy"I-SIMs (Scheme 1, Fig. 1) of guanidine-based ligand $\mathrm{L}[\mathrm{L}=$ tris(2-hydroxybenzylidene)triaminoguanidine] having formulas $\left[\mathrm{DyLCl}(\mathrm{DMF})_{2}\right] \cdot \mathrm{DMF} \cdot \mathrm{CH}_{3} \mathrm{OH}$ $\left[\mathrm{DyL}_{2}\left(\mathrm{CH}_{3} \mathrm{OH}\right)_{2}\right] \mathrm{Br} \cdot \mathrm{H}_{2} \mathrm{O} \cdot 3 \mathrm{CH}_{3} \mathrm{OH}$ $\left[\mathrm{DyL}_{2}\left(\mathrm{H}_{2} \mathrm{O}\right)_{2}\right] \mathrm{SCN} \cdot 3 \mathrm{H}_{2} \mathrm{O} \cdot \mathrm{CH}_{3} \mathrm{OH}$
(3) reaction conditions with changes in the coordinated solvents and lattice counter anions. These clusters provide a unique opportunity to probe the relaxation dynamics influenced by the distinct coordinated solvents and counter anions. Magnetic studies showed that compound $\mathbf{1}$ does not reveal slow magnetic relaxation while compounds 2-4 exhibit dynamic single-molecule magnetic behaviors with effective energy barriers of 207.3 (2), 222.5 (3) and 311.7 K (4), respectively, in the absence of a static magnetic field. Furthermore, (1), theoretical calculations were performed to investigate their (2), distinct magnetic performance, which is related to differences and in lattice counter anions and/or coordinate solvent molecules, affecting the coordinated geometry around the Dy"lI ion.

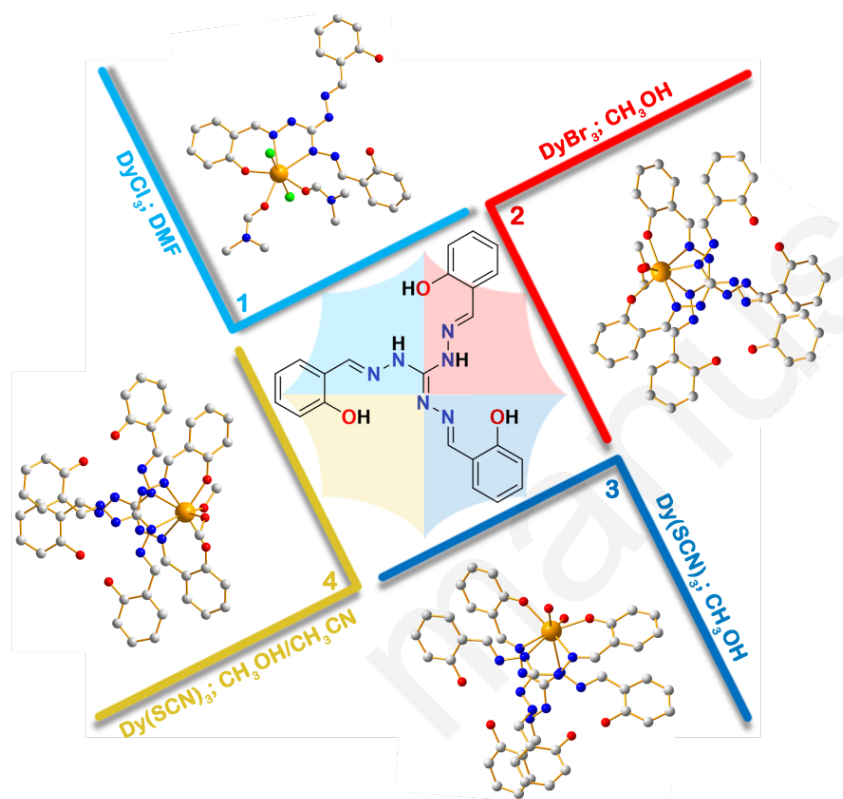

Scheme 1 Synthetic procedure of complexes 1-4 along with their single crystal structures (color codes: C, gray; Dy, light orange; O, red; Cl, bright green; N, blue), hydrogen atoms and lattice solvents and counter anions have been omitted for clarity.

\section{Experimental section}

\section{Materials and methods}

All solvents and chemicals were purchased from available commercial sources of analytical grade and used without further purification. Ligand $L$ was synthesized as reported in literature. ${ }^{27}$ Elemental analyses for $\mathrm{C}, \mathrm{H}$, and $\mathrm{N}$ were carried out on a Perkin-Elmer 2400 analyzer. Magnetic susceptibility measurements were carried out on polycrystalline sample with a Quantum Design MPMS-XL7 SQUID magnetometer in the temperature range of $1.9-300 \mathrm{~K}$ equipped with a $7 \mathrm{~T}$ magnet. Direct-current (dc) measurements were measured in the temperature range of $1.9-300 \mathrm{~K}$ with an external magnetic field of $1000 \mathrm{Oe}$, and alternating-current (ac) measurements were carried out in a $3.0 \mathrm{Oe}$ ac field oscillating with frequencies from 1 to $1000 \mathrm{~Hz} .{ }^{36}$

\section{Synthesis of $\left[\mathrm{DyLCl}_{2}(\mathrm{DMF})_{2}\right] \cdot \mathrm{DMF} \cdot \mathrm{CH}_{3} \mathrm{OH}(1)$.}

$\mathrm{DyCl}_{3} \cdot 6 \mathrm{H}_{2} \mathrm{O}(0.10 \mathrm{mmol})$ and ligand $\mathrm{L}(0.10 \mathrm{mmol})$ was mixed in DMF $(3 \mathrm{ml})$ followed by $\mathrm{Et}_{3} \mathrm{~N}(0.10 \mathrm{mmol})$. After $3 \mathrm{~h}$ of stirring at room temperature the mixture was filtered out and methanol vapors were allowed to diffuse slowly to get good quality yellowish color block-shaped crystals of $\mathbf{1}$ after one week. Elemental Anal. Calcd. for $\mathrm{C}_{32} \mathrm{H}_{44} \mathrm{Cl}_{2} \mathrm{DyN}_{9} \mathrm{O}_{7}$ (1) $(\mathrm{MW}=$ 900.16): C, 42.70; H, 4.93; N, 14.01. Found: C, 42.68; H, 4.90; N, 14.02 .

\section{Synthesis of $\left[\mathrm{DyL}_{2}\left(\mathrm{CH}_{3} \mathrm{OH}\right)_{2}\right] \mathrm{Br} \cdot \mathrm{H}_{2} \mathrm{O} \cdot 3 \mathrm{CH}_{3} \mathrm{OH}$ $\left.\left[\mathrm{DyL}_{2}\left(\mathrm{H}_{2} \mathrm{O}\right)_{2}\right] \mathrm{SCN} \cdot 3 \mathrm{H}_{2} \mathrm{O} \cdot \mathrm{CH}_{3} \mathrm{OH}\right)$ $\left[\mathrm{DyL}_{2}\left(\mathrm{CH}_{3} \mathrm{OH}\right)_{2}\right] \mathrm{SCN} \cdot \mathrm{CH}_{3} \mathrm{CN} \cdot \mathrm{CH}_{3} \mathrm{OH}$ (4).}

To synthesize complex 2, $\mathrm{DyBr}_{3} \cdot 6 \mathrm{H}_{2} \mathrm{O}(0.10 \mathrm{mmol})$ and ligand $\mathbf{L}$ $(0.10 \mathrm{mmol})$ were dissolved in methanol $(15 \mathrm{ml})$ followed by $\mathrm{Et}_{3} \mathrm{~N}(0.10 \mathrm{mmol})$. The resultant solution was stirred for $3 \mathrm{~h}$ at room temperature and filtered out. The slow evaporation of the filtrate causes to grow the very clear yellow color suitable crystals for single crystal measurements after 3-4 days in quantitative yield. Complexes 3 and $\mathbf{4}$ were also obtained by adopting a similar procedure as for $\mathbf{2}$, only replacing the corresponding dysprosium salts; $\mathrm{Dy}(\mathrm{SCN})_{3} \cdot 6 \mathrm{H}_{2} \mathrm{O}$ for $\mathbf{3}$ while $\mathbf{4}$ was synthesized similarly as $\mathbf{3}$ by replacing only methanol 
solvent with equimolar ratios of methanol and acetonitrile (10 $\mathrm{ml}: 10 \mathrm{ml}$ ).

Elemental Anal. Calcd. For $\mathrm{C}_{49} \mathrm{H}_{60} \mathrm{BrDyN}_{12} \mathrm{O}_{12}$ (2) (MW = 1251.50): C, 47.03; H, 4.83; N, 13.43. Found: C, 47.01; H, 4.85; $\mathrm{N}, 13.42$.
Elemental Anal. Calcd. for $\mathrm{C}_{46} \mathrm{H}_{46} \mathrm{DyN}_{13} \mathrm{O}_{12} \mathrm{~S}$ (3) (MW = 1167.52): C, 47.32; H, 3.97; N, 15.60. Found: C, 47.30; H, 3.94; N, 15.62 .

Elemental Anal. Calcd. For $\mathrm{C}_{50} \mathrm{H}_{53} \mathrm{DyN}_{14} \mathrm{O}_{9} \mathrm{~S}(4)(\mathrm{MW}=1188.62)$ : C, 50.52; H, 4.49; N, 16.50. Found: C, 50.51; H, 4.45; N, 16.52 .

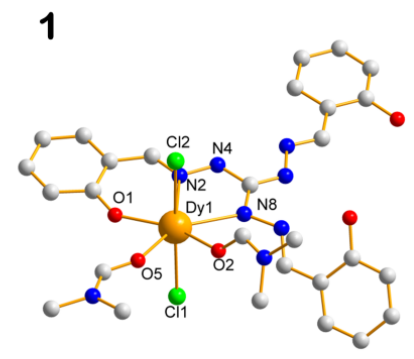

Not SMM

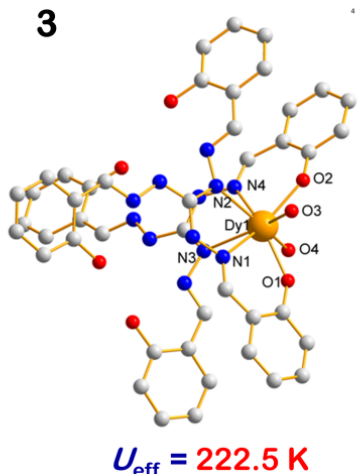

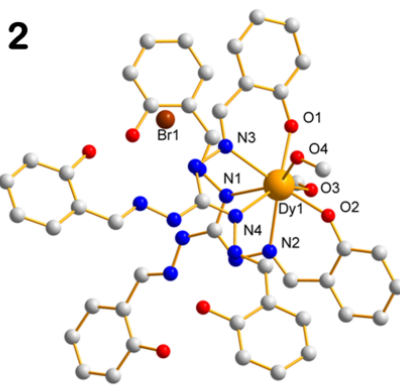

$U_{\text {eff }}=207.3 \mathrm{~K}$

4

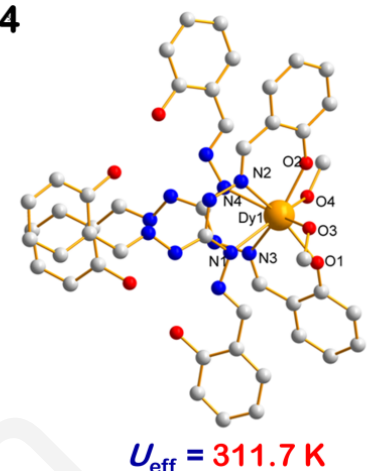

Fig. 1 Molecular structures of complexes 1-4. Hydrogen atoms, lattice solvents and counter anions are omitted for clarity.

\section{Crystallography}

Single crystals of 1-4 were mounted on glass fibers under a microscope, and diffraction data were obtained at corresponding temperatures (see Table S1) using a Bruker AXS D8 Venture single-crystal diffractometer equipped with graphite-monochromatized $\mathrm{Mo} / \mathrm{Cu} \mathrm{K} \alpha(\lambda=0.71073 / 1.54178)$ in liquid $\mathrm{N}_{2}$. The molecular drawings and mean plane analysis were obtained from the DIAMOND (version 3.1). The structure was solved by direct methods, SHELXT and refined by full-matrix least-squares techniques based on $F^{2}$ (SHELXL) in the Olex2 package. ${ }^{37,} 38$ The crystallographic data for 1-4 are available as Supporting Information. CCDC: 1999242, 1999244-1999246 of complexes 1-4 also contain the crystallographic data for this paper can be obtained free of charge from the Cambridge Crystallographic Data Centre via www.ccdc.cam.ac.uk/data_request/cif. Crystal data, structural refinement parameters, and selected bond distances and angles are listed in Tables S1-S4.

\section{$A b$ initio calculations.}

The wavefunction theory (WFT) calculations were performed using the complete-active space (CAS) self-consistent field (SCF) approach $^{39}$ as implemented in the OpenMolcas software package. ${ }^{40}$ The calculations were first carried out at the scalar relativistic (SR) level using the second-order Douglas-Kroll-Hess scalar relativistic Hamiltonian, ${ }^{41-43}$ in combination with the all electron atomic natural orbital relativistically contracted basis set (ANO-RCC). ${ }^{44,} 45$ The basis sets were contracted to the triple- $\zeta$ plus polarization (TZP) quality for the Dy and $\mathrm{Cl}$ atoms, as well as for the $\mathrm{N}$ and $\mathrm{O}$ atoms coordinated to the metal center $(D y=25 \mathrm{~s} 22 \mathrm{p} 15 \mathrm{~d} 11 \mathrm{f} 4 \mathrm{~g} 2 \mathrm{~h} / 8 \mathrm{~s} 7 \mathrm{p} 4 \mathrm{~d} 3 \mathrm{f} 2 \mathrm{~g} 1 \mathrm{~h} ; \quad \mathrm{Cl}=$ $17 s 12 p 5 d 4 f 2 g / 5 s 4 p 2 d 1 f ; N, O=14 s 9 p 5 d 3 f 2 g / 4 s 3 p 2 d 1 f$ ), to the double- $\zeta$ plus polarization (DZP) quality for the $\mathrm{C}, \mathrm{N}$ and $\mathrm{O}$ atoms $(\mathrm{C}, \mathrm{N}, \mathrm{O}=14 \mathrm{~s} 9 \mathrm{p} 5 \mathrm{~d} 3 \mathrm{f} 2 \mathrm{~g} / 3 \mathrm{~s} 2 \mathrm{p} 1 \mathrm{~d})$, and to the double- $\zeta$ quality for the $\mathrm{H}$ atoms $(\mathrm{H}=8 \mathrm{~s} 4 \mathrm{p} 3 \mathrm{~d} 1 \mathrm{f} / 2 \mathrm{~s})$. The calculations employed the state-averaged formalism at the SR level by taking into account the 21 sextet, the 224 quartet, and the 490 doublet spin states arising from the 9 electrons spanning the seven $4 f$ orbitals of the Dy"II ion. The spin-orbit coupling (SOC) was then introduced by a state interaction within the basis of spin-orbit free states using the restricted active space state interaction (RASSI) approach. ${ }^{46}$ Herein the SOC matrix is diagonalized using the calculated 21 SR sextet, 224 SR quartet, and the 98th lowest SR doublet spin states. The EPR $g$-factors were calculated according to reference as implemented in the RASSI module of OpenMolcas, ${ }^{47}$ whereas the magnetic susceptibility and magnetization calculations were performed using the Single-Aniso module of OpenMolcas. ${ }^{48}$ 

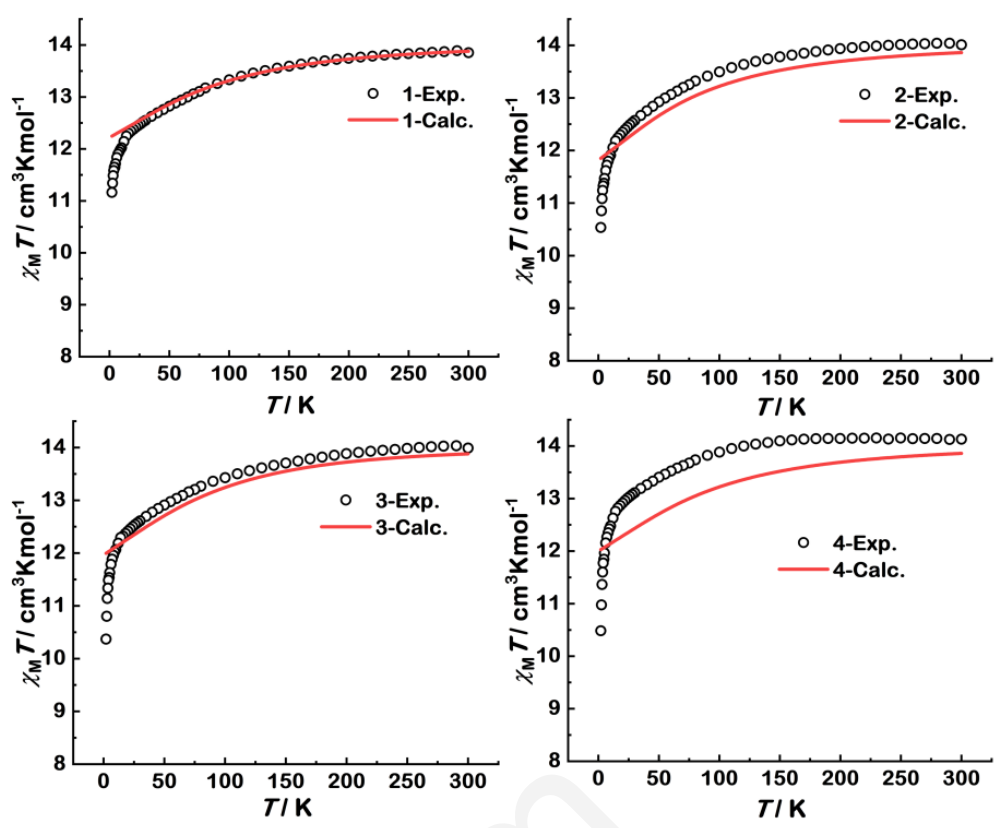

Fig. 2 Temperature dependence $\chi_{\mathrm{M}} T$ plots measured at $1 \mathrm{kOe}$ for $\mathbf{1 - 4}$. The solid lines correspond to the calculated values.

The WFT calculations were performed on the structures determined by X-ray spectroscopy. However, the position of the hydrogen atoms were optimized with the help of Kohn-Sham density functional theory by using the Amsterdam Density Functional (ADF) software package.49, 50 These calculations utilized the scalar all-electron zeroth-order regular approximation (ZORA) ${ }^{51}$ along with the spin-restricted formalism by replacing the Dy"II centers by Y"II ones. The PBE52, 53 functional (Perdew-Burke-Ernzerhof) from the generalized gradient approximation was employed along with the triple- $\zeta$ polarized Slater-type orbital (STO) all-electron basis set, with one set of polarization function for all atoms (TZP). ${ }^{54}$

The influence of the neighboring Dy"l centers in the crystal structures were investigated by calculating the dipolar coupling constants (JIP). Indeed, if one assumes that the Dy'II centers are sufficiently far away from each other, their magnetic interactions could be simply reduced to a coupling between the two magnetic dipoles. Therefore, the dipolar coupling between two Dy"l ions $i$ and $j$ is described by:

$$
J^{D I P}=\frac{\mu_{B}^{2}}{R^{3}}\left[\left(g_{i} \cdot g_{j}-3\left(g_{i} \cdot R\right)\left(g_{j} \cdot R\right)\right)\right]
$$

where $\mu_{\mathrm{B}}$ is the Bohr magneton, $\boldsymbol{R}$ a unit vector parallel to the $i-j$ direction, and $g_{i}$ and $g_{j}$ are the EPR $g$-factors of the $i$ and $j$ Dy'II centers within the Ising approximation, respectively.

\section{Results and discussion}

\section{Crystal Structure of Complexes 1-4.}

Compounds 1-4 have been prepared by controlling the amount of different solvents and/or using different Dy-salts (see Scheme 1 for details). Single crystal X-ray diffraction analyses show that compound $\mathbf{1}$ crystallizes in the orthorhombic space group $\left(P n a 2_{1}\right)$, while compounds 2-4 reveal to the triclinic system with space group $P-1$ (Table $\mathrm{S} 1$ ).

The mononuclear compound $\mathbf{1}$ is seven-coordinated, packaged by a set of three donors from the singly deprotonated ligand $\mathrm{L}(-\mathrm{ONN}-)$ and two coordinating DMF molecules in an equatorial plane while two $\mathrm{Cl}^{-}$anions are trapped at axial positions to complete the coordination sphere with two molecules of lattice solvent DMF and $\mathrm{CH}_{3} \mathrm{OH}$ (Fig. 1). The seven coordinate Dy"l' is in a $D_{5 h}$ pentagonal bipyramidal geometry, as confirmed by continuous shape measures analyses ${ }^{5-57}$ which give an estimate of the distortion from the ideal polyhedron, giving a value of 1.275 (Fig. S5, Table S5). ${ }^{15}$ The axial Dy-Cl distances are 2.679(3) and 2.631(4) $\AA$ while the equatorial $\mathrm{Dy}-\mathrm{O} / \mathrm{N}$ distances fall in the range of 2.156(7)-2.550(9) A for complex 1 (Table S2).

Compounds $\mathbf{2}$ and $\mathbf{4}$ display similar coordination packing (Fig. S1-S3), and only differ in counter anion $\mathrm{Br}^{-}$for 2; $\mathrm{SCN}^{-}$ for 4). Both compounds are eight-coordinated, six coordination sites ( 2 times -NNO-) from two singly deprotonated ligands in a trans fashion and two $\mathrm{O}$ donors from two $\mathrm{CH}_{3} \mathrm{OH}$ molecules to accomplish the inner coordination sphere along with one 
$\mathrm{H}_{2} \mathrm{O}$ and three $\mathrm{CH}_{3} \mathrm{OH}$ lattice molecules in complex 2 and one $\mathrm{CH}_{3} \mathrm{OH}$ and one $\mathrm{CH}_{3} \mathrm{CN}$ lattice molecules in complex 4 (Fig. 1). The continuous shape measurements ${ }^{55-57}$ reveal the $D_{2 \mathrm{~d}}$ triangular dodecahedron geometries giving the values of 0.709 and 0.891 for $\mathbf{2}$ and 4, respectively (Fig. S5, Table S6). The Dy1-O1 and Dy1-O2 (deprotonated $\mathrm{O}$ of L) distances are 2.246(5), 2.164(6) $\AA$ and 2.241(5), 2.173(6) $\AA$; Dy1-O3 and Dy1-O4 distances (O of $\mathrm{CH}_{3} \mathrm{OH}$ ) are 2.475(6), 2.460(6) $\AA$ and 2.481(6), 2.445(6) $\AA$ of 2 and 4. While the Dy-N bond lengths fall between 2.470(7)-2.534(7) $\AA$ and 2.492(7)-2.538(7) $\AA$ of 2 and 4 , respectively. The axial angles (deprotonated $O$ of two ligands) 01-Dy1-O2 are $112.9^{\circ}$ and $115.4^{\circ}$ for complexes 2 and 4, respectively. The angles among O4-Dy1-O3 (O of solvent molecules) are $132.7(5)^{\circ}$ for $\mathbf{2}$ and $129.01(2)^{\circ}$ for $\mathbf{4}$ (see Table S4). The slight differences of bond lengths and bond angles between complexes $\mathbf{2}$ and $\mathbf{4}$ may be induced by the different metal salts used in the synthesis. Interestingly, the 3-D topologies of complexes $\mathbf{2}$ and $\mathbf{4}$ in a given direction are the same whatever the counter anions in the crystal lattice (Fig. S1-S3).

Compound $\mathbf{3}$ also displays somewhat similar inner coordination environment, with the difference in coordinating solvent molecules and some lattice solvent (Fig. 1). In complex 3 two $\mathrm{H}_{2} \mathrm{O}$ molecules are coordinated with the central Dy"l' ion along with six coordination sites (2 times -NNO-) from two singly deprotonated ligands in a trans fashion. Again, continuous shape measurements reveal the $D_{2 \mathrm{~d}}$ triangular dodecahedron geometry giving the value of 0.891 for complex 3 (Table S6). The Dy1-O1 and Dy1-O2 (deprotonated O of L) distances are 2.208(5) and 2.248(6) $\AA$; Dy1-O3 and Dy1-O4 distances $\left(\mathrm{O}\right.$ of $\mathrm{H}_{2} \mathrm{O} / \mathrm{CH}_{3} \mathrm{OH}$ ) are 2.4268(4) and 2.399(6) $\AA$ of complex 3. While the $\mathrm{Dy}-\mathrm{N}$ bond lengths fall between 2.459(7)-2.551(7) $\AA$ of 3. The axial angle (deprotonated O of two ligands) $01-D y 1-02$ is $115.80(2)^{\circ}$ and the angle among O4-Dy1-03 (O of solvent molecules) is $131.36(18)^{\circ}$ for 3 (see Table S5). Compared with complexes 2 and 4, the 3-D topology of complex 3 along $a, b$ and $c$ axes (Fig. S4) shows totally distinct crystal packing mode. These minute differences between complexes 2-4 in angles and bond lengths that originate from coordinating different solvent molecules may affect the anisotropy axes which are mainly responsible for their distinct magnetic properties.

\section{Magnetic studies.}

\begin{tabular}{lll}
\hline \multicolumn{3}{l}{ Table 1. Direct current magnetic data for complexes 1-4. } \\
\hline $\begin{array}{l}\chi_{\mathrm{M}} T \text { expected for non-interacting } \\
\text { ions/measured at } 300 \\
\mathrm{~K} / \mathrm{measured} \text { at } 1.9 \mathrm{~K}\left(\mathrm{~cm}^{3} \mathrm{~K} \mathrm{~mol}^{-1}\right)\end{array}$ & $\begin{array}{l}\text { Magnetization } \\
\text { at } 1.9 \mathrm{~K} \text { and } 7 \\
\mathrm{~T}\left(\mu_{\mathrm{B}}\right)\end{array}$ \\
\hline $\mathbf{1}$ & $14.17 / \mathbf{1 4 . 3 4} / 11.57$ & 5.39 \\
$\mathbf{2}$ & $14.17 / \mathbf{1 4 . 7 6 / 1 1 . 1 0}$ & 5.66 \\
$\mathbf{3}$ & $14.17 / \mathbf{1 4 . 3 3 / 1 0 . 7 7}$ & 5.23 \\
$\mathbf{4}$ & $14.17 / \mathbf{1 3 . 9 9 / 1 0 . 3 7}$ & 5.52 \\
\hline
\end{tabular}

Variable-temperature direct-current (dc) magnetic susceptibility $\left(\chi_{\mathrm{M}} T\right)$ experiments were performed on polycrystalline samples of all five complexes in a temperature range of 1.9-300 $\mathrm{K}$ in an applied field of 1000 Oe (Table 1 and Fig. 2). The observed $\chi_{\mathrm{M}} T$ values at room temperature are 14.36, 14.76, 14.33 and $13.99 \mathrm{~cm}^{3} \mathrm{~K} \mathrm{~mol}^{-1}$ for complexes 1-4, respectively, compared with the expected value of $14.17 \mathrm{~cm}^{3} \mathrm{~K}$ $\mathrm{mol}^{-1}$ for an isolated Dy'II ion ( $S=5 / 2, L=5, g=4 / 3$ and ${ }^{6} \mathrm{H}_{15 / 2}$ ). By decreasing the temperature, the $\chi_{\mathrm{M}} T$ values decrease gradually until $\sim 25 \mathrm{~K}$, and then decrease rapidly to minima of 11.57, 11.10, 10.77 and $10.37 \mathrm{~cm}^{3} \mathrm{~K} \mathrm{~mol}^{-1}$ for complexes 1-4, respectively. The decrease in the $\chi_{\mathrm{M}} T$ values in 1-4 could be attributed to crystal field splitting, mainly the progressive quenching of excited Dy'll Stark-sublevels and/or weak intra/intermolecular interactions. ${ }^{58-61}$ Comparatively, the $\chi_{\mathrm{M}} T$ curves for complexes 1-4 are slightly different at low temperatures which can be ascribed to different intermolecular Dy...Dy distances, resulting in distinct antiferromagnetic dipole-dipole interactions among the molecules (Fig. 2 and Table S11).

The field-dependent magnetization of 1-4 was examined at $1.9 \mathrm{~K}$ in the field range of $0-7 \mathrm{~T}$ (Fig. S6). The highest measured value of magnetization for 1-4 are 5.39, 5.66, 5.23, and $5.52 \mu_{\mathrm{B}}$, respectively. These values are lower than the expected saturation value of $10 \mu_{\mathrm{B}}$ for a free Dy'III ion, ${ }^{58-62}$ implying the presence of considerable ligand-field effects. At $1.9 \mathrm{~K}$, complexes 2-4 display well defined butterfly-shaped hysteresis loops whereas no obvious hysteresis of $M$ vs. $H$ data is observed for complex $\mathbf{1}$ (Fig. S7). 

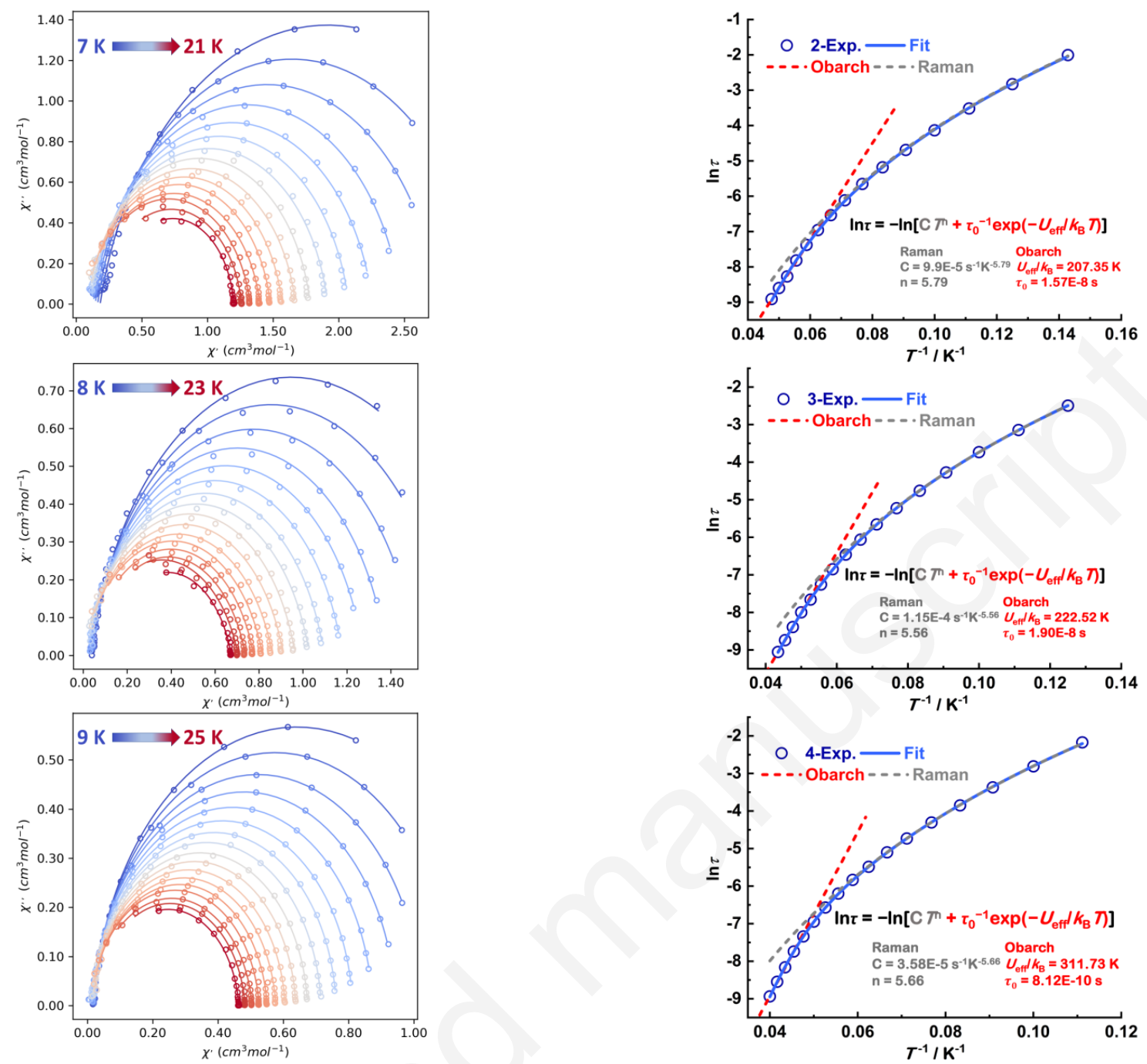

Fig. 3 Cole-Cole plots with solid lines as generalized Debye fits within indicated temperatures for 2-4 (top to bottom), respectively.

To study the magnetization dynamics of $\mathbf{1 - 4}$, ac magnetic susceptibility measurements were performed under zero field with a small oscillating ac field of 3 Oe. For complex 1, no obvious out-of-phase $\left(\chi^{\prime \prime}\right)$ ac susceptibility signals can be observed (Fig. S8, left), implying the fast quantum tunneling relaxation (QTM). By contrast, all 2-4 show a series of well-defined $\chi^{\prime \prime}$ maxima as a function of frequency and temperature with $\chi^{\prime \prime}$ peaks clearly observable up to 19, 20 and $25 \mathrm{~K}$ for complexes 2-4, respectively (Fig. S8, and S9). In contrast to $\mathbf{2}$ and $\mathbf{3}$, both $\chi^{\prime}$ and $\chi^{\prime \prime}$ components for $\mathbf{4}$ nearly vanish as the temperature decreases down to $2 \mathrm{~K}$. This phenomenon can be taken as a clear indication that zero-field quantum tunneling of magnetization is completely suppressed in complex 4. While decreasing the temperature, both the components increase again for complexes $\mathbf{2}$ and $\mathbf{3}$. The appearance of this characteristic in complexes $\mathbf{2}$ and $\mathbf{3}$ relates the start of quantum tunneling of the magnetization, which is usually happened in lanthanide SMMs. ${ }^{63}$ also been investigated by calculating their frequency dependencies under zero dc field. The corresponding $\chi^{\prime}$ and $\chi^{\prime \prime}$ plots of 2-4 reveal obvious frequency dependencies peaks (Fig. S10 and S11). The Cole-Cole fitting plots (Fig. 3) of 2-4 based on frequency-dependent with the generalized Debye model ${ }^{58-62}$ displayed nonsymmetrical semicircles. The parameters found are in the range of $0.06-0.14$ (7-21 K), 0.13-0.19 (8-23 K) and 0.033-0.073 (9-25 K), for 2-4 respectively, giving a narrow distribution of relaxation times (Tables S7-S9). The Arrhenius plots were constructed by using the extracted relaxation times ( $\tau$ ) (Fig. 4). The $\ln \tau$ vs. $T^{-1}$ plots were fitted considering the Orbach and Raman process to yield the corresponding effective energy barrier for relaxation $U_{\text {eff }} / k_{\mathrm{B}}=207.35 \mathrm{~K}\left(144.11 \mathrm{~cm}^{-1}\right)$ and $\tau_{0}=1.57 \times 10^{-8} \mathrm{~s}$ for 2 ; $U_{\text {eff }} / k_{\mathrm{B}}=222.52 \mathrm{~K}\left(154.65 \mathrm{~cm}^{-1}\right)$ and $\tau_{0}=1.90 \times 10^{-8} \mathrm{~s}$ for 3 and $U_{\text {eff }} / k_{\mathrm{B}}=311.73 \mathrm{~K}\left(216.65 \mathrm{~cm}^{-1}\right)$ and $\tau_{0}=8.12 \times 10^{-10} \mathrm{~s}$ for 4 . (for details, see the insets of Fig. 4 of corresponding extracted parameters for 2-4).

Theoretical calculations. 
In order to provide more insight into the differences observed in the magnetic properties of complexes 1-4, $a b$ initio calculations were carried out on each complex using the multireference CASSCF approach (see computational details). The calculated KD energies, the $g$-factors and the composition of the ground state (GS) and first excited state (ES) of complexes 1-4 are presented in Table S10. Interestingly, in all complexes the GS is strongly axial and close to a pure Ising case with contribution from the $M_{J}= \pm 15 / 2$ state of $92,95,96$ and $98 \%$ in 2, 3, 4 and 1, respectively. Consequently, the g-factors associated to these GSs are strongly anisotropic with a parallel component $\mathrm{g}_{z}$ of ca. 19.6 and perpendicular components $g_{x}$ and $g_{y}$ close to null. The first excited KDs lie above the GS at ca. $180 \mathrm{~cm}^{-1}$ and are also strongly axial with a large contribution from the $M_{\jmath}= \pm 13 / 2$ state. However, this contribution decreases from $92 \%$ in 1 to 78,76 and $70 \%$ in $\mathbf{4 ,} 2$ and 3, respectively. Due to this axial character in both states, the principal magnetic axes between the ground and first excited KDs for all Dy sites are fairly collinear, forming a small angle of less than $11^{\circ}$ for $\mathbf{1}, \mathbf{2}$ and $\mathbf{4}$, and $16.9^{\circ}$ for complex 3 . Representations of the magnetic transition moments between the lowest states of 1-4 are shown in Fig. S13. From the calculated transition moments, in the four investigated compounds an Orbach mechanism for the relaxation of the magnetization is only favored up to the first excited state, where strong thermally-assisted quantum tunneling of the magnetization occurs. Therefore, no drastic differences in the calculated transition moments are found for the isolated complexes, preventing the rationalization of the measured dynamical magnetic properties. Nevertheless, the calculated dipolar magnetic coupling constants with the closest nearest Dy centers in the crystal structures are given in Table S11. Interestingly, the different crystal packing between $\mathbf{1}$ on one side and 2-4 on the other side, leads to a much smaller anti-ferromagnetic interaction in $\mathbf{1}$ than in the other complexes, which may induce different dynamic magnetic properties.

\section{Structural correlation.}

Complexes 2-4 are actually isomorphous to each other but with different dynamic magnetic properties. For complexes 2 and 4, although the different counter anions $\left(\mathrm{Br}^{-}\right.$and $\left.\mathrm{SCN}^{-}\right)$ and solvent molecules $\left(\mathrm{CH}_{3} \mathrm{OH}, \mathrm{H}_{2} \mathrm{O}\right.$ and $\left.\mathrm{CH}_{3} \mathrm{OH} / \mathrm{CH}_{3} \mathrm{CN}\right)$ in the crystal lattice, the packing mode of the main structures along $a$, $b$ and $c$ axes is totally identical (Fig. S1-S3). The Dy...Dy inter-molecular distances of $5.889 \AA$ (2) and $5.886 \AA$ (4) are also very close. However, complex 4 shows higher energy barrier of $311 \mathrm{~K}$ than that observed in complex 2 of $207 \mathrm{~K}$. Detailed insight into the magnetic anisotropic axes of $\mathbf{2}$ and $\mathbf{4}$ were obtained through ab initio calculations, the principal axes of the ground doublets in $\mathbf{2}$ and $\mathbf{4}$ are all oriented towards two phenol $\mathrm{O}(\mathrm{O} 1, \mathrm{O} 2)$ atoms of the two deprotonated ligands (Fig. S12). Through further study on the structures of complexes 2 and 4, O1-Dy1-O2 angle of $115.4^{\circ}$ for complex 4 is slightly larger than that detected in complex $\mathbf{2}$ of $112.9^{\circ}$, which induces the stronger axial anisotropy of complex 4 (Table 2). Indeed, the ground state has stronger axial magnetic anisotropy $\left(g_{z}=\right.$
19.592) with negligible transversal components and purer $M_{\jmath}=$ $\pm 15 / 2$ KDs for complex 4 (95.6\%) than that calculated in $\mathbf{2}\left(g_{\mathrm{z}}=\right.$ $19.442,92.5 \%$, Table S10). Therefore, stronger axial magnetic anisotropy and larger 01-Dy1-O2 angle account for the higher energy barrier for complex 4 . While comparing complexes 2 and 3, the axial Dy1-O1 and Dy1-O2 bond lengths in complex 2 of 2.246 and $2.164 \AA$ are slightly shorter than those detected in complex 3 of 2.208 and $2.248 \AA$, which will more or less reduce the axial magnetic anisotropy in $\mathbf{3}$. However, the larger O1-Dy1-O2 angle in complex $\mathbf{3}$ (115.8 ) compared to complex $2\left(112.9^{\circ}\right)$ will induce stronger axial anisotropy of complex $\mathbf{3}$ on the other hand. Additionally, complex 3 displays the larger axial magnetic anisotropy $\left(g_{z}=19.565\right)$ and a purer $M_{J}= \pm 15 / 2$ KDs $(95.1 \%)$ than that calculated in complex $2\left(g_{z}=19.442\right.$, $92.5 \%)$. Collectively both these effects are assumed to balance the energy barriers with the slightly higher of $222 \mathrm{~K}$ than $207 \mathrm{~K}$ for complexes $\mathbf{3}$ and 2, respectively. Finally, when comparing $\mathbf{3}$ and 4, the axial Dy1-O1 and Dy1-O2 bond lengths in complex 3 of 2.208 and $2.248 \AA$ are slightly longer than in complex 4 of 2.241(18) and 2.173(19) $\AA$ which significantly induce the stronger axial anisotropy of complex 4. Furthermore, complex 4 displays the largest axial magnetic anisotropy $\left(g_{z}=19.592\right.$, 95.6\%) than that calculated in complex $3\left(g_{z}=19.565,95.1 \%\right)$. Consequently, both these effects are responsible for higher energy barrier for $4(311 \mathrm{~K})$ than $3(222 \mathrm{~K})$, respectively.

Table 2. Important bond lengths $(\AA)$ and angles $\left({ }^{\circ}\right)$ of axially coordinated $\mathrm{O}$ of $\mathbf{L}$ for 2-4 along with other calculated important parameters.

\begin{tabular}{cccc} 
complex & $\mathbf{2}$ & $\mathbf{3}$ & $\mathbf{4}$ \\
\hline Dy1-01 & $2.246(5)$ & $2.208(5)$ & $2.241(18)$ \\
Dy1-02 & $2.164(6)$ & $2.248(6)$ & $2.173(19)$ \\
average & 2.205 & 2.228 & 2.207 \\
O2-Dy1-01 & $112.9(2)$ & $115.8(2)$ & $115.40(7)$ \\
$g_{z}$ & 19.442 & 19.565 & 19.592 \\
$M_{J}$ & 92.5 & 95.1 & 95.6 \\
$\tau_{0}(\mathrm{~s})$ & $1.57 \times 10^{-8}$ & $1.90 \times 10^{-8}$ & $8.12 \times 10^{-10}$ \\
$U_{\text {eff }}(\mathrm{K})$ & 207.35 & 222.52 & 311.73 \\
\hline
\end{tabular}

\section{Conclusion}

In summary, for the first time four new mononuclear Dy"II complexes 1-4, with guanidine-based ligand have been successfully prepared by fluctuating the reaction conditions. Interestingly, although these complexes display similar dc magnetic properties, different magnetic dynamic behaviors are observed. The compound $\mathbf{1}$ did not show SMM behavior due to the weekly coordinated two $\mathrm{Cl}^{-}$anions at axial positions. The magnetic properties of $\mathbf{1}$ can be improved by replacing the week $\mathrm{Cl}^{-}$anions with strong negatively charged co-ligands at axial positions. In the case of complexes $\mathbf{2 - 4}$, they display somewhat isomorphous structures owing eight coordinated $\mathrm{N}_{4} \mathrm{O}_{4}$ environment with triangular dodecahedron $D_{2 d}$ symmetry. 
AC magnetic studies showed that the single-ion magnetic behavior (SIMs) under zero DC applied field with effective energy barriers $\left(U_{\text {eff }}\right)$ of $207.3(2), 222.5$ (3) and $311.7 \mathrm{~K}(4)$, respectively. The diverse ac magnetic properties may result from the different types of coordinated solvent molecules and counter anions, which slightly affect the intermolecular interactions and coordination geometries, thus affecting the directions of the easy axes on each dysprosium site. These results offer an interesting but a possible opportunity into the fine-tuning the magnetic properties of SIMs by slightly modifying the coordination geometry through introducing different auxiliary solvent ligands and counter anions into the crystal lattice. Furthermore, we are also trying to replace the different coordinated solvents and counter anions as in case of 3 and 4 to further explore their effects on single molecule magnetic behavior.

\section{Conflicts of interest}

The authors declare no conflict of interest.

\section{ORCID}

Xiao-Lei Li: 0000-0002-1648-9459

Frédéric Gendron: 0000-0002-1896-3978

Boris Le Guennic: 0000-0003-3013-0546

Jinkui Tang: 0000-0002-8600-7718

\section{Acknowledgements}

We thank the National Natural Science Foundation of China (Grants 21525103, 21871247 and 21801237) and Key Research Program of Frontier Sciences, CAS (Grant ZDBS-LY-SLH023) for financial support. J. T. gratefully acknowledges support of the Royal Society-Newton Advanced Fellowship (NA160075). B. A is grateful for the support through CAS-TWAS President's Fellowship. F. G. and B. L. G. thanks the French GENCI/IDRIS-CINES centers for high-performance computing resources, and acknowledge the Stratégie d'Attactivité Durable (SAD18006 - LnCPLSMM) for financial support.

\section{References}

1. A. B. Canaj, M. K. Singh, E. R. Marti, M. Damjanovic, C. Wilson, O. Cespedes, W. Wernsdorfer, G. Rajaraman and M. Murrie, Chem. Commun., 2019, 55, 5950-5953.

2. A. K. Bar, P. Kalita, M. K. Singh, G. Rajaraman and V. Chandrasekhar, Cood. Chem. Rev., 2018, 367, 163-216.

3. Z. Zhu, M. Guo, X.-L. Li and J. Tang, Coord. Chem. Rev., 2019, 378, 350-364.

4. S. G. McAdams, A.-M. Ariciu, A. K. Kostopoulos, J. P. S. Walsh and F. Tuna, Cood. Chem. Rev., 2017, 346, 216-239.

5. J. L. Liu, Y. C. Chen and M. L. Tong, Chem. Soc. Rev., 2018, 47, 2431-2453.

6. F.-S. Guo, A. K. Bar and R. A. Layfield, Chem. Rev., 2019, 119, 8479-8505.
7. Y. S. Ding, T. Han, Y. Q. Hu, M. Xu, S. Yang and Y. Z. Zheng, Inorg. Chem. Front., 2016, 3, 798-807.

8. C. Gao, A. Genoni, S. Gao, S. Jiang, A. Soncini and J. Overgaard, Nat. Chem., 2020, 12, 213-219.

9. Y. S. Meng, S. D. Jiang, B. W. Wang and S. Gao, Acc. Chem. Res., 2016, 49, 2381-2389.

10. F.-S. Guo, B. M. Day, Y.-C. Chen, M.-L. Tong, A. Mansikkamaki and R. A. Layfield, Science, 2018, 362, 1400-1403.

11. C. A. P. Goodwin, F. Ortu, D. Reta, N. F. Chilton and D. P. Mills, Nature, 2017, 548, 439-442.

12. F.-S. Guo, B. M. Day, Y.-C. Chen, M.-L. Tong, A. Mansikkamaki and R. A. Layfield, Angew. Chem. Int. Ed., 2017, 56, 11445-11449.

13. W. Wernsdorfer and R. Sessoli, Science, 1999, 284, 133-135.

14. M. Shiddiq, D. Komijani, Y. Duan, A. Gaita-Arino, E. Coronado and S. Hill, Nature, 2016, 531, 348-351.

15. A. B. Canaj, S. Dey, E. R. Mart, C. Wilson, G. Rajaraman and M. Murrie, Angew. Chem. Int. Ed., 2019, 58, 14146-14151.

16. A. M. Ako, V. Mereacre, R. Clerac, W. Wernsdorfer, I. J. Hewitt, C. E. Anson and A. K. Powell, Chem. Commun., 2009, 544-546.

17. D. N. Woodruff, R. E. Winpenny and R. A. Layfield, Chem. Rev., 2013, 113, 5110-5148.

18. G. A. Craig and M. Murrie, Chem. Soc. Rev., 2015, 44, 2135-2147.

19. S. T. Liddle and J. van Slageren, Chem. Soc. Rev., 2015, 44, 6655-6669.

20. L. Sun, S. Zhang, Z. J. Jiang, Q. Yang, S. P. Chen, Y. Q. Zhang, W. Y. Wang, Q. Wei and G. Xie, Dalton Trans., 2017, 46, 11159-11165.

21. L. F. Chibotaru, L. Ungur, C. Aronica, H. Elmoll, G. Pilet and D. Luneau, J. Am. Chem. Soc., 2008, 130, 12445-12455.

22. I. M. Muller and D. Moller, Eur. J. Inorg. Chem., 2005, 257-263.

23. I. M. Muller, S. Spillmann, H. Franck and R. Pietschnig, Chem. Eur. J., 2004, 10, 2207-2213.

24. I. M. Muller, D. Moller and K. Focker, Chem. Eur. J., 2005, 11, 3318-3324.

25. I. M. Oppel and K. Foecker, Angew. Chem. Int. Ed., 2008, 47, 402-405.

26. I. M. Muller, R. Robson and F. Separovic, Angew. Chem. Int. Ed., 2001, 40, 4385-4386.

27. I. M. Muller and R. Robson, Angew. Chem. Int. Ed., 2000, 39, 4357-4359.

28. W. Plass, Coord. Chem. Rev., 2009, 253, 2286-2295.

29. M. Böhme, A. E. Ion, B. Kintzel, A. Buchholz, H. Görls and W. Plass, Z. Anorg. Allg. Chem., 2020, 646, 999-1009.

30. D. Plaul, M. Boehme, S. Ostrovsky, Z. Tomkowicz, H. Goerls, W. Haase and W. Plass, Inorg. Chem., 2018, 57, 106-119.

31. M. Böhme, D. Schuch, A. Buchholz, H. Görls and W. Plass, Z. Anorg. Allg. Chem., 2020, 646, 166-174.

32. J. Hamblin, F. Tuna, S. Bunce, L. J. Childs, A. Jackson, W. Errington, N. W. Alcock, H. Nierengarten, A. Van Dorsselaer, E. Leize-Wagner and M. J. Hannon, Chem. Eur. J., 2007, 13, 9286-9296.

33. E. T. Spielberg, A. Gilb, D. Plaul, D. Geibig, D. Hornig, D. Schuch, A. Buchholz, A. Ardavan and W. Plass, Inorg. Chem, 2015, 54, 3432-3438. 
34. B. Kintzel, M. Boehme, J. Liu, A. Burkhardt, J. Mrozek, A. Buchholz, A. Ardavan and W. Plass, Chem. Commun., 2018, 54. 12934-12937.

35. M. L. Abraham, A. C. Schulze, A. Korthaus and I. M. Oppel, Dalton Trans, 2013, 42, 16066-16072.

36. G. A. Bain and J. F. Berry, J. Chem. Educ., 2008, 85, 532.

37. G. M. Sheldrick, Acta Crystallogr. A., 2015, 71, 3-8.

38. G. M. Sheldrick, Acta Crystallogr. C., 2015, 71, 3-8.

39. B. O. Roos, P. R. Taylor and P. E. M. Sigbahn, Chem. Phys., 1980, 48, 157-173.

40. I. Fdez. Galván, M. Vacher, A. Alavi, C. Angeli, F. Aquilante, J. Autschbach, J. J. Bao, S. I. Bokarev, N. A. Bogdanov, R. K. Carlson, L. F. Chibotaru, J. Creutzberg, N. Dattani, M. G. Delcey, S. S. Dong, A. Dreuw, L. Freitag, L. M. Frutos, L. Gagliardi, F. Gendron, A. Giussani, L. González, G. Grell, M. Guo, C. E. Hoyer, M. Johansson, S. Keller, S. Knecht, G. Kovačević, E. Källman, G. Li Manni, M. Lundberg, Y. Ma, S. Mai, J. P. Malhado, P. Å. Malmqvist, P. Marquetand, S. A. Mewes, J. Norell, M. Olivucci, M. Oppel, Q. M. Phung, K. Pierloot, F. Plasser, M. Reiher, A. M. Sand, I. Schapiro, P. Sharma, C. J. Stein, L. K. Sørensen, D. G. Truhlar, M. Ugandi, L. Ungur, A. Valentini, S. Vancoillie, V. Veryazov, O. Weser, T. A. Wesołowski, P.-O. Widmark, S. Wouters, A. Zech, J. P. Zobel and R. Lindh, J. Chem. Theory Comput., 2019, 15, 5925-5964.

41. M. Douglas and N. M. Kroll, Ann. Phys., 1974, 82, 89-155.

42. B. A. Hess, Phys. Rev. A, 1985, 32, 756-763.

43. B. A. Hess, Phys. Rev. A, 1986, 33, 3742-3748.

44. P.-O. Widmark, P.-Å. Malmqvist and B. O. Roos, Theor. Chim. Acta, 1990, 77, 291-306.

45. B. O. Roos, R. Lindh, P.-Å. Malmqvist, V. Veryazov and P.-O. Widmark, J. Phys. Chem. A, 2004, 108, 2851-2858.

46. P. Å. Malmqvist, B. O. Roos and B. Schimmelpfennig, Chem. Phys. Lett., 2002, 357, 230-240.

47. H. Bolvin, Chem. Phys. Chem., 2006, 7, 1575-1589.

48. L. F. Chibotaru and L. Ungur, J. Chem. Phys., 2012, 137, 064112.

49. C. Fonseca Guerra, J. G. Snijders, G. te Velde and E. J. Baerends, Theor. Chem. Acc., 1998, 99, 391-403.

50. G. te Velde, F. M. Bickelhaupt, E. J. Baerends, C. Fonseca Guerra, S. J. A. van Gisbergen, J. G. Snijders and T. Ziegler, J. Compt. Chem. , 2001, 22, 931-967.

51. E. v. Lenthe, E. J. Baerends and J. G. Snijders, J. Chem. Phys., 1993, 99, 4597-4610.

52. J. P. Perdew, K. Burke and M. Ernzerhof, Phys. Rev. Lett., 1996, 77, 3865-3868.

53. J. P. Perdew, K. Burke and M. Ernzerhof, Phys. Rev. Lett., 1997, 78, 1396-1396.

54. E. Van Lenthe and E. J. Baerends, J. Comput. Chem., 2003, 24, 1142-1156.

55. H. Zabrodsky, S. Peleg and D. Avnir, J. Am. Chem. Soc. 1993, 115, 8278-8289.

56. S. Alvarez, P. Alemany, D. Casanova, J. Cirera, M. Llunell and D. Avnir, Coord. Chem. Rev., 2005, 249, 1693-1708.

57. A. Ruiz-Martínez, D. Casanova and S. Alvarez, Chem. Eur. J., 2008, 14, 1291-1303.

58. S. Zhang, W. J. Mo, J. W. Zhang, Z. Q. Zhang, B. Yin, D. W. Hu and S. P. Chen, Inorg. Chem., 2019, 58, 15330-15343.

59. J. K. Tang, I. Hewitt, N. T. Madhu, G. Chastanet, W. Wernsdorfer, C. E. Anson, C. Benelli, R. Sessoli and A. K. Powell, Angew. Chem. Int. Ed., 2006, 45, 1729-1733.
60. P. Zhang, L. Zhang, C. Wang, S. F. Xue, S. Y. Lin and J. K. Tang, J. Am. Chem. Soc., 2014, 136, 4484-4487.

61. X. Y. Liu, X. F. Ma, W. Z. Yuan, P. P. Cen, Y. Q. Zhang, J. Ferrando-Soria, G. Xie, S. P. Chen and E. Pardo, Inorg. Chem., 2018, 57, 14843-14851.

62. X. F. Ma, B. B. Chen, Y. Q. Zhang, J. H. Yang, Q. Shi, Y. L. Ma and X. Y. Liu, Dalton Trans., 2019, 48, 12622-12631.

63. Y. J. Gao, G. F. Xu, L. Zhao, J. K. Tang and Z. L. Liu, Inorg. Chem., 2009, 48, 11495-11497. 


\section{SYNOPSIS TOC}

Diverse relaxation dynamics of a series Dy'II-based SIMs that result from the coordinated molecules and counter anions were elucidated by structural analysis, magnetic investigations and $a b$ initio calculations.

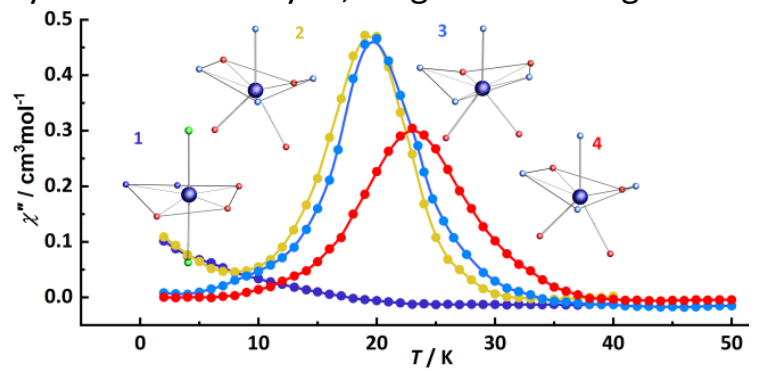

